\title{
Climatology of Orographic Precipitation Gradients in the Contiguous Western United States
}

\author{
Lucas Bohne, Courtenay Strong, And W. James Steenburgh \\ Department of Atmospheric Sciences, University of Utah, Salt Lake City, Utah
}

(Manuscript received 24 September 2019, in final form 14 May 2020)

\begin{abstract}
Orographic precipitation gradients (OPG) relating to the increase or decrease in precipitation amount with elevation are not well studied or analyzed except for case examples. A quality controlled daily OPG dataset for the western United States that is based on a linear regression framework of gauge precipitation observations and elevation for a 39-yr time period was created and analyzed to identify spatial and temporal patterns and variability in OPG and some of the drivers of variability on seasonal, annual, interannual, and climatological time scales. Most locations in the western United States experience positive OPG during most of the year, exhibiting an annual cycle with the highest magnitude of OPG in the winter season and lowest magnitude of OPG in the summer season. Coastal locations tend to have OPG with higher magnitude and larger variability in OPG than do interior locations during cool seasons. Empirical orthogonal function analysis identifies two principal components that account for $33 \%$ of the variability in a subset of the OPG dataset, and these modes of variability are related to precipitation amount and atmospheric circulation over the Pacific Ocean. Comparison of daily OPG with similarly calculated 3-day and monthly OPG identifies that OPG magnitudes are sensitive to the choice of length of the precipitation accumulation period.
\end{abstract}

\section{Introduction}

Complex terrain regions around the world cover nearly one-half of the land surface area and contribute to nearly one-half of surface runoff (Chow et al. 2013). These natural water towers are important source regions of water resources extending into areas featuring less complex terrain, providing domestic and agricultural water supply through drier summer months through snowmelt. In the contiguous western United States, much of the surface runoff comes from cool-season precipitation, with an average of $53 \%$ (with estimates ranging from $35 \%$ to $90 \%$ by catchment) of surface runoff deriving from the melting of accumulated coolseason snow during spring and summer (Li et al. 2017; Serreze et al. 1999).

Not only are regions of complex terrain important for water resources, but liquid and frozen precipitation produced by storms in these regions strongly affect recreation, transportation, tourism, and local economies. The diversity in terrain features across the western United States provides challenges in understanding the

Corresponding author: Lucas Bohne, lucas.bohne@utah.edu role of topography on spatial and temporal distributions of precipitation. Understanding the distribution is important because the accumulation of precipitation across elevational gradients (especially as snow) can affect the timing and amount of water resource availability through the warm season (Dettinger et al. 2004). While improved computing advances for numerical weather prediction have increased resolution and accuracy of precipitation forecasts, many weather models still have biases in interior complex terrain areas of the western United States (Gowan et al. 2018).

Several research projects have investigated the relationship between precipitation and elevation in the western United States. Lull and Ellison (1950) used precipitation observations in central Utah to develop a linear relationship between precipitation and elevation. Others have used more complex combinations of precipitation observations and terrain features to determine typical precipitation distributions on daily, monthly, annual, and climatological time scales, such as those from the Parameter-Elevation Regressions on Independent Slopes Model (PRISM) Climate Group. These gridded analyses for weather and climate variables have been useful to downscale numerical weather 
model output or climate model output to produce finescale products based on climatological distributions of meteorological variables (Daly et al. 1994, 2008; Praskievicz 2017; Wang et al. 2017; Zhu et al. 2017; Lewis et al. 2017). High-resolution, gridded precipitation analyses are useful for validating weather/climate models and developing improved analyses but varying gridded analyses show large differences in precipitation amounts and distributions, especially in complex terrain of the western United States (Henn et al. 2018).

One way to quantify the distribution of precipitation across elevation gradients is with the use of an orographic precipitation gradient (OPG). This quantity can describe the increase or decrease of precipitation with elevation and the strength of the precipitation differences across elevational ranges. The use of OPG has been utilized in several case studies to compare precipitation amounts in complex terrain regions (e.g., Dettinger et al. 2004; Lundquist et al. 2010). Others have compared precipitation values across topography but not used OPG per se.

This relationship/distribution of precipitation (essentially OPG) is also known to vary within storms, between precipitation events, and seasonally (Steenburgh 2003; Dettinger et al. 2004). Therefore, even using weather model output that has been downscaled using the fixed climatological precipitation-elevation relationship for that day (from gridded analyses mentioned above) introduces some uncertainties to precipitation forecast products (Lewis et al. 2017). Studies on the impacts of localized or large-scale weather features on the precipitation-elevation relationship have taken place (Dettinger et al. 2004; Lundquist et al. 2010; Smith and Barstad 2004; Neiman et al. 2002), but they are often limited to a small number of precipitation events or seasons, and use varied amounts of precipitation observations across varying time scales. Case studies on orographic precipitation have identified moisture transport, barrier height, wind speed and direction, El Niño-Southern Oscillation (ENSO), atmospheric stability, and cloud microphysics as some of the drivers affecting precipitation placement and orographic enhancement (Dettinger et al. 2004; Smith and Barstad 2004; Huning and Margulis 2018; Luce et al. 2013).

While gridded precipitation analyses have been analyzed in hindsight to determine typical local OPG over a portion of the western United States (Praskievicz and Bartlein 2014), they have not been analyzed for the broader region of the western United States. The patterns of spatial and temporal variability have been studied in terms of the cumulative annual distribution of snowfall by Huning and Margulis (2017) in the Sierra Nevada, rainfall gradients using observations (Brunsdon et al. 2001; Burt and Holden 2010; Sevruk 1997) in various regions around the world, and in future climate scenarios (Singh and Goyal 2016), but have not been well studied to understand the relationship between precipitation and elevation on shorter (daily) time scales.

This study uses station precipitation observations and elevations in a linear regression framework to develop time series of daily OPG. Station groupings for linear regressions are determined by a facet algorithm that takes into account the orientation of the topography. These time series of OPG have areal coverage across a majority of the complex topography of the western United States and most of the time series have daily values for multiple decades. This paper describes the method used in creating the OPG dataset and quality control procedures to produce consistent and reliable records of daily OPG. These time series of OPG are then analyzed on seasonal time scales to determine climatological OPG values for locations in the western United States. Empirical orthogonal function (EOF) analysis is also used to determine some of the main drivers of year-to-year variability in OPG across the western United States for a 39-yr period. The goal is to provide additional and expanded insight from the case studies on orographic precipitation mentioned above to include a majority of the continental western United States and gain understanding of the important but not well understood relationship between precipitation and elevation.

\section{Data and methods}

\section{a. Daily precipitation observations}

Gauge precipitation observations from the Global Historical Climatology Network (GHCN)-Daily, version 3.22, dataset were used for all stations in the region between $100^{\circ}$ and $125^{\circ} \mathrm{W}$ and between $30^{\circ}$ and $50^{\circ} \mathrm{N}$ reporting at least once during the time period from 1 January 1979 to 31 March 2018. This resulted in a total of 15629 precipitation observing stations with values originating from a variety of continental, national, regional, and local instrumentation networks, including the U.S. Automated Surface Observing System (ASOS); Community Collaborative Rain, Hail and Snow Network (CoCoRaHS); the U.S. Department of Agriculture (USDA) Natural Resources Conservation Service (NRCS) Snowpack Telemetry (SNOTEL) network; and NOAA/National Weather Service (NWS) Cooperative Observer Program (COOP) manual and automated measurements, among others (Menne et al. 2012a). Each precipitation observing station is provided a source code through GHCN-Daily, but some stations may have multiple network affiliations 
TABLE 1. GHCN-Daily precipitation observing station source networks, number of stations from each network, and percentage of total stations (15629 total). For more information about GHCN-Daily data sources, see Menne et al. (2012b).

\begin{tabular}{lrr}
\hline \hline \multicolumn{1}{c}{ GHCN-Daily station source } & Count & Percent of total stations \\
\hline Community Collaborative Rain, Hail and Snow Network (CoCoRaHS) & 9970 & 63.8 \\
U.S. Cooperative Summary of the Day & 3543 & 22.7 \\
Snowpack Telemetry (SNOTEL) & 795 & 5.1 \\
Environment and Climate Change Canada & 686 & 4.4 \\
U.S. Cooperative Summary of the Day (via WxCoder3) & 281 & 1.8 \\
WBAN/ASOS Summary of the Day from the National Climatic Data Center & & 1.0 \\
$\quad$ Integrated Surface Data (ISD) & 128 & \\
National Centers for Environmental Information (NCEI) Reference & & \\
$\quad$ Network Database & 28 & \\
High Plains Regional Climate Center & 20 & 12 \\
U.S. First-Order Summary of the Day & 6 & 0.8 \\
International collection & 3 & $<0.1$ \\
Global Summary of the Day & 3 & $<0.1$ \\
Datzilla official additions or replacements & & $<0.1$ \\
Climate Database Modernization Program (CDMP) Cooperative & & $<0.1$ \\
$\quad$ Summary of the Day & & \\
\hline
\end{tabular}

or sources. The most common source code from each station was used to inventory the sources of stations, and the number of stations from each source within GHCN-Daily is provided in Table 1. A majority of the stations are from either CoCoRaHS, U.S. Cooperative Summary of the Day, Environment and Climate Change Canada (some facets extend across international borders), or SNOTEL. Daily precipitation values correspond to the accumulated precipitation for a $24-\mathrm{h}$ period, but observation times and reporting times vary by network, so time periods for stations from different networks may not always represent the midnight to midnight local time period. For this analysis and the development of the OPG dataset, however, we assume that the dates attributed to the daily precipitation values from $\mathrm{GHCN}$ are representative of the daily precipitation for that date.

As a sensitivity analysis, we explored two other options for addressing the unknown reporting periods: 1 ) omit stations with unknown reporting periods, and 2) lengthen the precipitation accumulation period to lessen the impact of potentially inconsistent reporting periods across different networks. We present associated results from this sensitivity analysis in section $2 \mathrm{f}$.

These precipitation data undergo internal quality control checks for spatial and temporal consistency, duplicates, climatological outliers, negative values, and many others as highlighted in the GHCN-Daily documentation (Durre et al. 2008, 2010), and any daily value that fails one of these checks is assigned a quality flag. We omitted from our analysis daily precipitation observation with a quality flag from the GHCN-Daily internal quality control, which accounted of $0.036 \%$ of total observations. In addition to the precipitation values, each station's latitude, longitude, and elevation were also retrieved from GHCN-Daily for use in analysis. The station locations used from the GHCNDaily database are shown in Fig. 1a.

\section{b. Elevation data and facet algorithm}

Digital elevation model (DEM) data from the Global 30 Arc-Second Elevation (GTOPO30) dataset from the U.S. Geological Survey (USGS) were used (EROSC 2017 ) with latitudinal extent from $25^{\circ}$ to $52^{\circ} \mathrm{N}$ and longitudinal extent from $95^{\circ}$ to $130^{\circ} \mathrm{W}$. Approximately 4-km resolution was obtained by using a sample factor of 5 , which used every fifth value from the original 30-arcsecond data grid. These elevation data served as the input to a facet algorithm, which allowed stations to be grouped in a spatially and topographically dependent fashion that closely followed the method of Gibson et al. (1997).

The facet algorithm method first involved smoothing the DEM and calculating the gradient of elevations in the zonal and meridional directions, then specifying a threshold for which gradients are essentially small enough to be considered flat. The flat threshold is userdefined and dependent on the domain of the DEM used in the faceting algorithm. Our DEM domain used as input to the facet algorithm encompassed large, flat areas of the Great Plains and the Pacific Ocean in addition to the complex terrain of the western United States, and therefore a majority of the meridional and zonal gradients were small. A pixel was defined to be flat if both its meridional and zonal gradient were less than the 70th percentile of the absolute value of gradients in the entire domain.

Meridional and zonal gradients were used to calculate a terrain facing direction for each grid point of the 

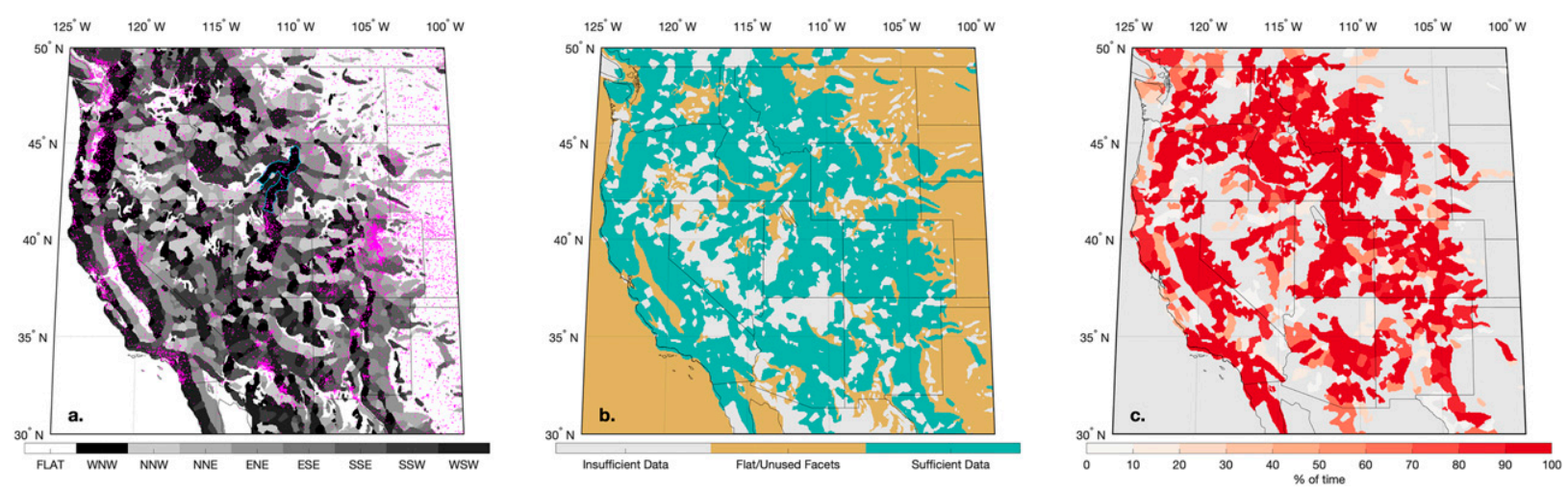

FIG. 1. (a) Facet terrain orientations (shaded) and GHCN-Daily station locations (magenta). A single facet that was split into two is outlined in blue near the Wyoming-Idaho border. (b) Data availability for facets, where insufficient data (white) means there are fewer than two stations on the facet for the entire period of record from 1 Jan 1979 to 31 Mar 2018, and sufficient data (blue green) means there is at least one day with at least two stations on the facet to calculate OPG during this period. Flat and/or unused facets are noted by tan. (c) For facets with sufficient data, the percentage of days in the period of record for which an OPG is calculated out of the total number of days with precipitation on the facet.

DEM, separated into eight bin directions with centers at secondary intercardinal directions (SID) (WSW, SSW, SSE, etc.) and inclusive of the values within $22.5^{\circ}$ on either side of the SID. A ninth bin was created for grid points determined to be flat. For each pixel in the grid, a $17-\mathrm{km}$ radius circular window was used to bin the pixel and its surroundings into terrain orientation frequency distributions. The circular window size guides the resulting facet sizes, with larger (smaller) circular windows producing fewer (more) facets overall with larger (smaller) spatial area. The $17-\mathrm{km}$ circular window radius was chosen to achieve reasonable resolution of the terrain while maintaining sufficient numbers of stations on each facet for OPG calculation that followed.

After terrain orientation frequency distributions were calculated, a multibranch decision tree was used to assign a facet direction corresponding to the SID centers mentioned above, but with more contiguous regions of identical terrain orientation than originally calculated from the raw gradients of elevation. Details of the multibranch decision tree from Gibson et al. (1997) were guidelines for determining whether the most frequent or second most frequent orientation was assigned to the grid point based on adjacent pixel values and sizes of frequency distributions for each terrain orientation. Image processing using the Moore neighbor-tracing algorithm modified by Jacob's stopping criteria identified contiguous regions of identical terrain orientation direction (Gonzalez et al. 2004). Then, each of these regions was labeled with a facet number and the facet boundaries in latitude-longitude coordinates were determined from the perimeter of each contiguous region using additional image processing (Haralick and Shapiro 1992).
The facet algorithm and image processing produced simple and physically plausible facet shapes in almost all cases. However, regions that met only at vertices of two diagonal pixels and did not share a common pixel edge were separated. In addition, one large facet near the Wyoming-Idaho border with an unusually complex shape was split into two facets based on groupings of stations inside the facet that coincided with a bend in the shape of the facet. The boundaries of the two resulting facets for this case are shown by blue outline in Fig. 1a. A total of 2292 facets were identified and assigned by the facet algorithm and image processing to be used in this analysis for the western United States.

\section{c. Station requirements for daily orographic precipitation gradients}

Each of the GHCN-Daily stations was assigned to its appropriate facet based on latitude/longitude coordinates of the stations in relation to the facet boundaries. Many facets with small spatial extent or in remote areas of the western United States contain very few stations or none at all. For these facets, the daily OPG was unable to be calculated due to insufficient data. To make the initial (i.e., prior to quality control) calculation of OPG, it was required that facets have at least two stations as well as a sum of station precipitation greater than zero for a daily OPG calculation. Facets having insufficient and sufficient data are shown in Fig. 1b. For days with sufficient data, a linear least squares regression between station precipitation amounts and station elevations was fit using

$$
P_{i}=b_{1} z_{i}+b_{0}+\varepsilon_{i}
$$



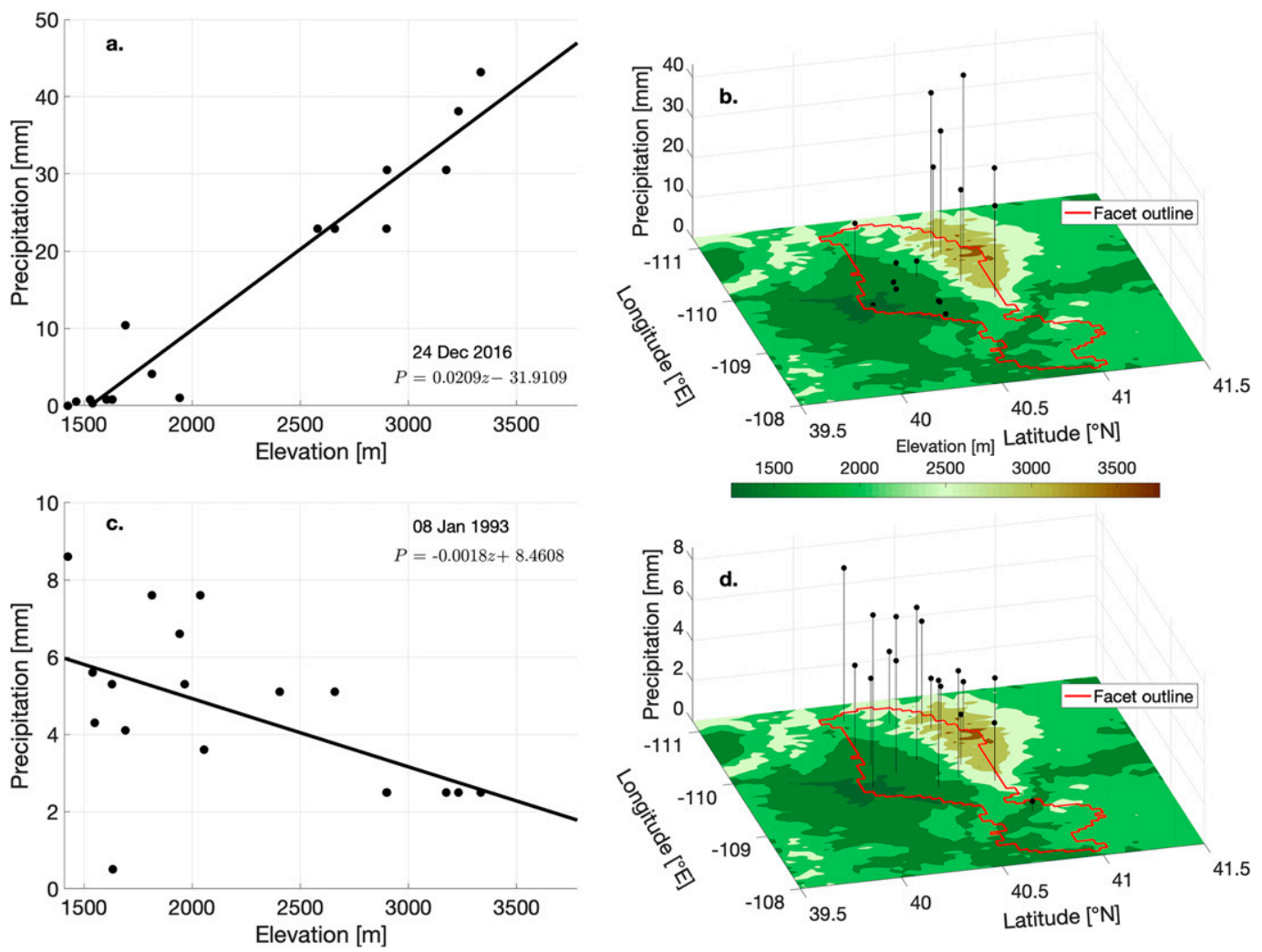

FIG. 2. Examples of daily precipitation-elevation regressions and equations for a facet in northern Utah that represents the south-facing slope of the Uinta Mountains for a day with (a) positive OPG and (c) negative OPG. (b),(d) The corresponding precipitation stem plots for station locations in relation to the topography and facet outline (looking westward along the crest of the mountain range) for these example days.

where the slope of this regression $b_{1}$ is the $\mathrm{OPG}, b_{0}$ is the regression $y$ intercept, $z_{i}$ is the elevation above sea level of the $i$ th station, $P_{i}$ is the precipitation amount of the $i$ th station, and $\varepsilon_{i}$ is the residual between the linear OPG estimate and the precipitation value of the $i$ th station. Values of OPG represent the increase or decrease in precipitation with increasing elevation on each facet for each day. Examples of regressions for a positive OPG day (24 December 2016) and a negative OPG day (8 January 1993) are shown in Fig. 2 for a facet in the Uinta Mountains of northern Utah. The day-specific regression equations are also included on this figure.

\section{d. Quality control procedures}

Raw OPG required quality control procedures to remove outliers and unrealistic OPG values. Poor quality and extreme OPG values mainly occurred due to lack of elevation span of stations in the facet in comparison to the full elevation range of the facet. To identify and eliminate these OPG values, we produced a cumulative distribution of the elevations on each facet using the grid points of the unsmoothed DEM. Then, the station elevations used in each daily regression were utilized to calculate the amount of the cumulative distribution from the DEM spanned by the stations for each day (cdf span). Based on visual inspection of each OPG time series, a minimum cdf span threshold of $40 \%$ was used to filter out unreliable daily OPG values on each facet and produce consistent OPG time series.

Eight facets required slightly higher minimum cdf span thresholds (ranging from $42 \%$ to $55 \%$ ) where the original $40 \%$ minimum was not successful at filtering out unreliable values. This procedure eliminated occasions where the addition of one or more stations on a facet created OPG magnitudes much different than those when cdf span was sufficient (typically later in the record when stations were added to additional elevations on the facet).

Several facets had periods of high magnitude OPG in the beginning of the record when few stations were used in the regression calculation, resulting in few degrees of freedom for the daily OPG values. By using the OPG magnitude and the generally higher cdf span from later in the record, we were able to determine the cdf span threshold to use and infer whether the OPG values at the beginning of the record were reliable. The final 

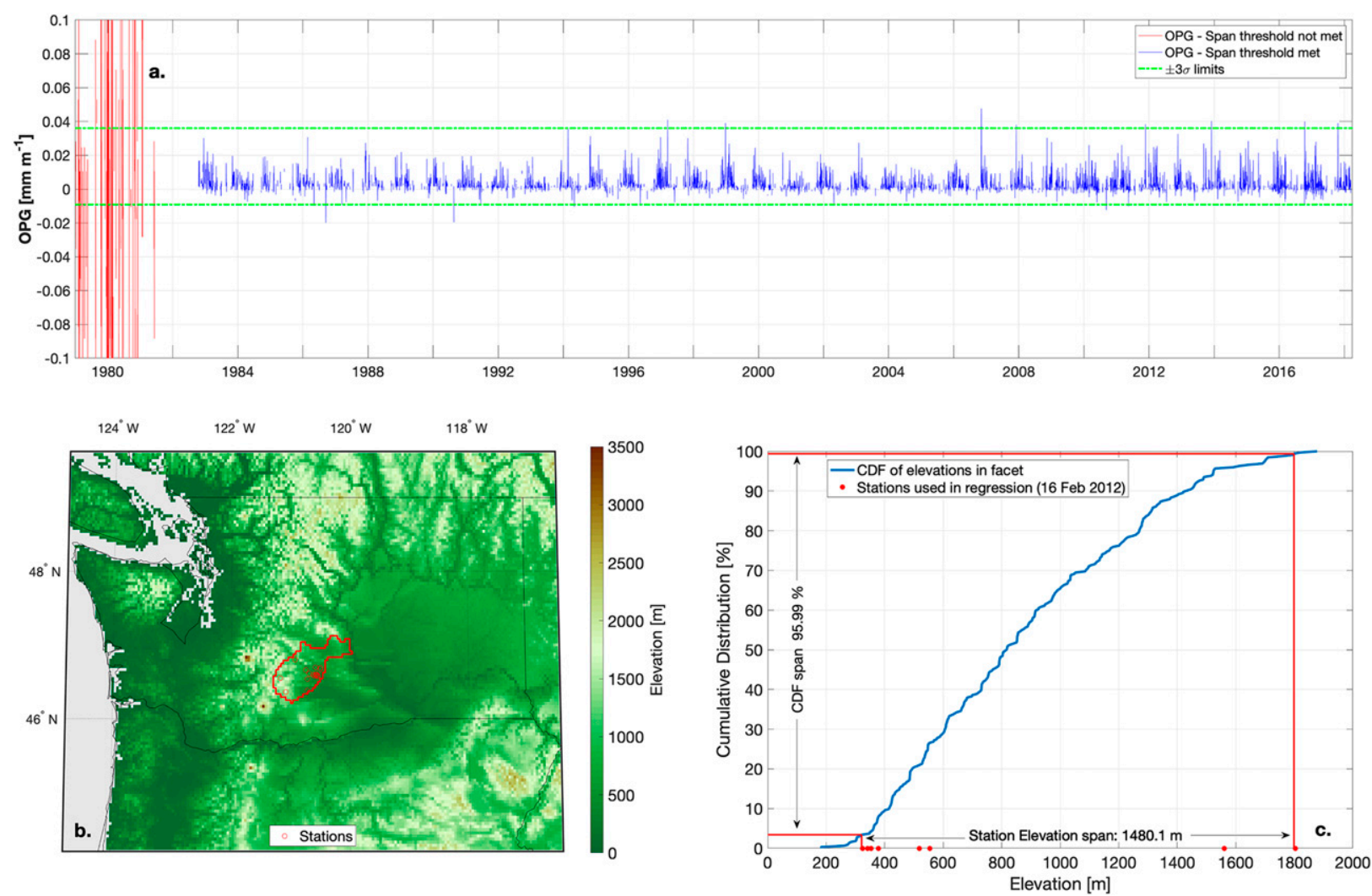

FIG. 3. Visualization of OPG time series for an example facet for the period 1 Jan 1979-31 Mar 2018: (a) Daily OPG values calculated from linear least squares regression for days with at least two stations on the facet. Blue and red values respectively indicate the station elevations that did and did not meet the cdf span threshold. Green lines indicate plus and minus 3 standard deviations $( \pm 3 \sigma)$. The final, quality controlled OPG time series for this facet includes the daily OPG values in blue that also are between the $\pm 3 \sigma$ bounds. (b) Location of example facet with facet boundaries, precipitation observing station locations, and elevation shading. (c) Example of daily cdf span calculation for $16 \mathrm{Feb} 2012$ with the cumulative distribution of elevations on the facet (blue) and stations/elevations used in daily OPG regression (red symbols). On this day, the stations used in the regression spanned $1480.1 \mathrm{~m}$, which corresponds to a cdf span of $95.99 \%$.

quality control to the OPG dataset involved the removal of OPG values outside of \pm 3 standard deviations for each facet for the entire available record after removal of values based on cdf span threshold was performed. The percentage of the time period from 1 January 1979 to 31 March 2018 for which daily quality controlled OPG is available is shown in Fig. 1c for each facet. Only 438 of the 2292 facets have OPG time series due to either the lack of station coverage to calculate OPG or the lack of sufficient cdf span to pass quality control. See Fig. 3 as a visualization of our quality control procedures including time periods with minimum cdf span threshold unmet/met.

\section{e. Base precipitation amount and dry layers}

In addition to precipitation increase/decrease with elevation, the linear regression coefficients of Eq. (1) provide detail into dry layers on facets based on the elevation at which precipitation starts/stops in relation to the facet elevations. Essentially, these upper and lower dry layers are calculated from $x$ intercepts of the regression in combination with the range of elevations on the facet. We refer to the lowest elevation at which precipitation occurs as $\chi_{\min }$ and the highest elevation at which precipitation occurs as $\chi_{\text {max }}$. The minimum and maximum elevation on the facet (from the DEM) are $z_{\min }$ and $z_{\max }$, respectively. Rearranging Eq. (1) for these cases yields

$\chi_{\min }=\left\{\begin{array}{lll}-b_{0} / b_{1}, & \text { if } & b_{1}>0\end{array}\right.$ and $z_{\min } \leq-b_{0} / b_{1} \leq z_{\max }$

and

$\chi_{\max }=\left\{\begin{array}{lll}-b_{0} / b_{1}, & \text { if } \quad b_{1}<0 \\ z_{\max }, & \text { if } & b_{0} \geq 0\end{array}\right.$ and $\quad z_{\min } \leq-b_{0} / b_{1} \leq z_{\max }$.

Days with positive OPG have precipitation increasing with elevation, and therefore no upper dry layer is 
present, and days with negative OPG have precipitation decreasing with elevation so that no lower dry layer is present. Daily regressions representing precipitation on the entire facet have $x$ intercepts outside of the range of elevations on the facet so $\chi_{\min }$ and $\chi_{\max }$ must be assigned to be the minimum or maximum facet elevation, respectively, to keep the upper/lower dry-layer depths greater than or equal to zero meters. In addition, since a negative value of $b_{0}$ would give a negative and unrealistic value of base precipitation $P_{0}$ for days with a lower dry layer and a positive OPG, the base precipitation is defined as

$$
P_{0}=\left\{\begin{array}{lll}
b_{1} z_{\min }+b_{0}, & \text { if } & \chi_{\min }=z_{\min } \\
0, & \text { if } & \chi_{\min }>z_{\min }
\end{array} .\right.
$$

Then, the daily depths of the upper dry layer $\delta z_{u}$ and lower dry layer $\delta z_{\ell}$ on each facet are

$$
\begin{aligned}
& \delta z_{u}=z_{\max }-\chi_{\max } \text { and } \\
& \delta z_{\ell}=\chi_{\min }-z_{\min } .
\end{aligned}
$$

As mentioned above, for days with the Eq. (1) regression having precipitation on the entire facet, both the upper and lower dry-layer depths are zero.

\section{f. Sensitivity analysis}

The calculations of daily OPG are sensitive to qualities of the station precipitation data such as reporting time, station placement, and network affiliation. Some instrumentation may have limitations with measuring certain precipitation types, measuring/reporting procedures, maintenance, or in certain weather conditions (undercatch in windy conditions, for example). This subsection describes a set of sensitivity analyses with associated results presented in section $3 \mathrm{a}$.

Since many stations/networks do not expressly identify the time cutoffs of the 24-h period for precipitation observation, we compared the daily OPG values with an OPG from a longer observing period time, as mentioned by Menne et al. (2012b). Specifically, a daily OPG identical to the daily OPG regression detailed in section $2 \mathrm{c}$ was calculated for each day and each facet, except using each station's 3-day total precipitation (sum of the previous day, current day, and next day). Using a 3-day precipitation amount expands the time period and may reduce the uncertainty and effect of having stations from varying networks (and varying reporting times) in the relatively short 24 -h accumulation period, which can overlap exactly or have several hours' difference. Expanding the precipitation amount used in the regression to a 3-day total produces time series with OPG for more days than the original, since an
OPG can also be calculated on days when precipitation does not occur on that specific day but occurs on the previous and/or next day. These 3-day OPG were quality controlled using the cdf span threshold identical to the single-day OPG.

Another option to reduce the uncertainty in OPG regressions based on reporting periods is to omit stations having unknown or unspecified reporting periods. This type of OPG dataset has OPG based only on stations with reporting periods from midnight to midnight or morning to morning and omits stations with unknown reporting times. This omission of stations reduces the number of facets with available OPG data from 438 to 316 (27\% decrease). Individual time series on the facets that remain are also shortened, mainly in the beginning of the record, due to lack of stations or cdf span. This omission of certain networks causes a loss of $32 \%$ of the daily OPG values that are present in the quality controlled original OPG dataset.

\section{g. EOF analysis}

Following Hannachi et al. (2007), empirical orthogonal function analysis (also known as principal component analysis) was performed by calculating the eigenvectors and eigenvalues of the spatial correlation matrix of winter-season [December-February (DJF)] mean OPG starting with winter 1980 (the 1980 winter season constitutes 1 December 1979-29 February 1980). The EOF analysis uses a subset of the OPG dataset of 120 nonflat facets with OPG values for all 39 winter seasons, providing spatial coverage that encompasses most areas in the western United States featuring significant topography.

\section{h. ERA-Interim reanalysis}

The ERA-Interim global atmospheric reanalysis dataset from the European Centre for Medium-Range Weather Forecasts (ECMWF; Dee et al. 2011) was used in this analysis for producing $500-\mathrm{hPa}$ geopotential height composites and developing spatial correlation maps based on EOF analysis. Daily 500-hPa geopotential height data from the 1200 UTC analysis period were retrieved from the ECMWF data access website for the Northern Hemisphere at $1^{\circ}$ horizontal resolution from January 1979 through March 2018.

\section{Results}

\section{a. Results of sensitivity analysis}

Before presenting the main results, we briefly explore the sensitivity of OPG to accumulation period and omission of stations with unspecified reporting periods 

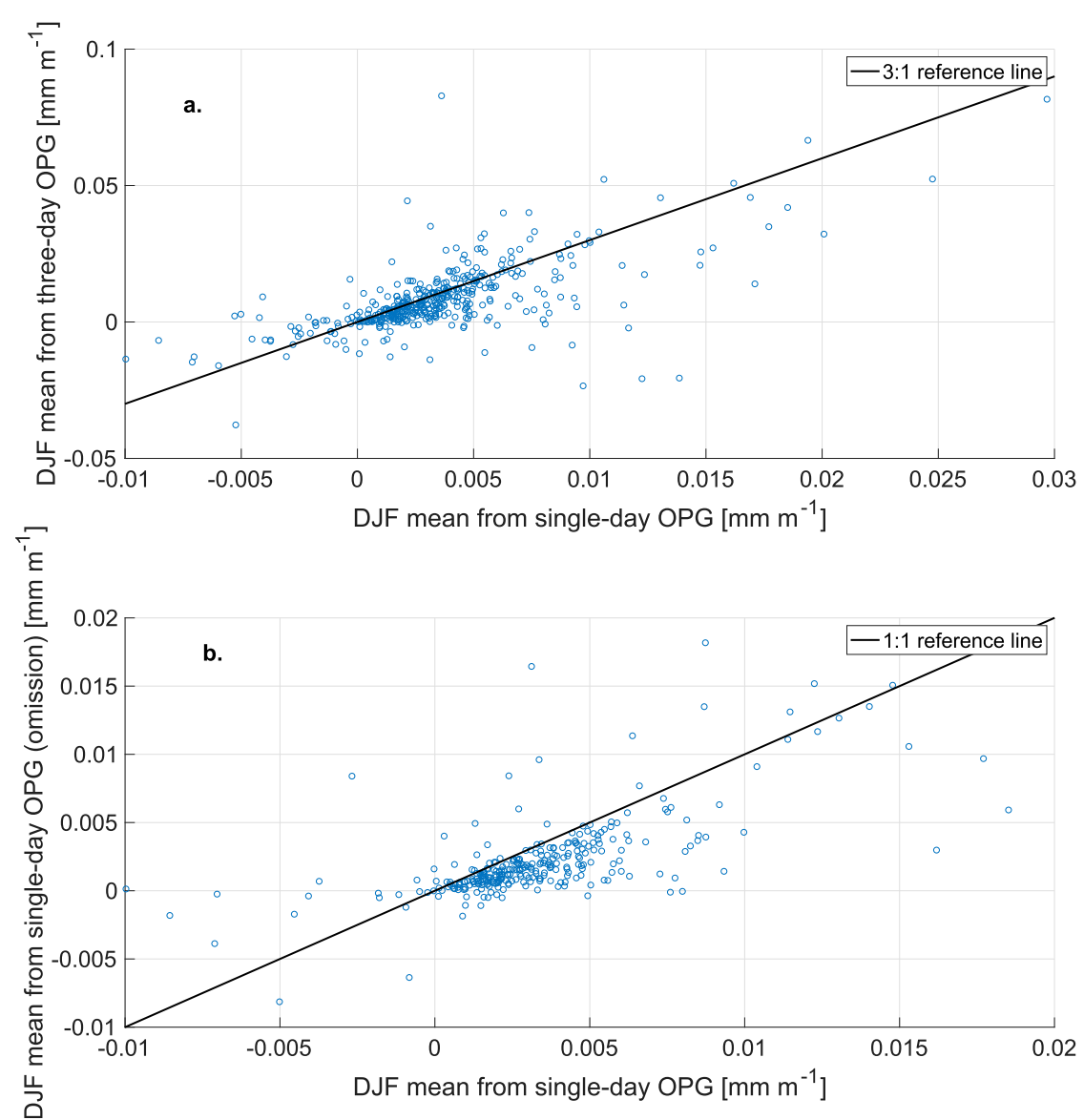

FIG. 4. (a) Comparison of winter (DJF) mean OPG values calculated with the single-day precipitation accumulation method used in this study (abscissa) and with a 3-day precipitation accumulation period calculated only for comparison (ordinate). (b) As in (a), but the ordinate shows winter mean OPG values calculated with stations having unknown precipitation reporting times omitted from the OPG calculation. In (a) and (b), each open circle is the result for one facet.

as detailed in section $2 \mathrm{f}$. The OPG based on the 3-day total is generally larger in magnitude than the original OPG, because higher precipitation totals allow for steeper orographic precipitation gradients. For example, low-elevation stations on a facet may receive no precipitation over three days while higher-elevation stations may receive precipitation on all three days, which would result in a larger difference between precipitation amounts across the elevations on a facet and thus a larger OPG. Because of this, the winter-season mean 3-day OPG is approximately 3 times the winter-season mean of the original single-day OPG (Fig. 4a). We see similar results to the OPG regression magnitudes using longer accumulation periods (e.g., monthly). The size of the OPG increase with accumulation period does depend on location. In general, the 3-day and monthly OPGs are about 4-5 times and 30-45 times, respectively, as large as the single-day OPG in the Pacific Northwest, northern
Rocky Mountains, and Sierra Nevada but only 2-3 times and 5-15 times, respectively, as large for more inland areas and in the southwestern United States.

The second sensitivity analysis was to omit networks with unspecified reporting periods. Mean winter-season OPG is generally decreased by about $0.001 \mathrm{~mm} \mathrm{~m}^{-1}$ from original single-day OPG on each facet when these networks are omitted from the OPG regression (Fig. 4b), but the spatial pattern of OPG is generally preserved even though many facet time series of OPG are eliminated. Also, as noted in section $2 \mathrm{f}$, this omission of networks causes a loss of $32 \%$ of the daily OPG values that are present in the quality controlled original OPG dataset.

\section{b. Central tendency, skew, spread, and annual cycle of $O P G$}

Spatial and seasonal patterns of OPG in the western United States are shown in Fig. 5 for nonflat facets 

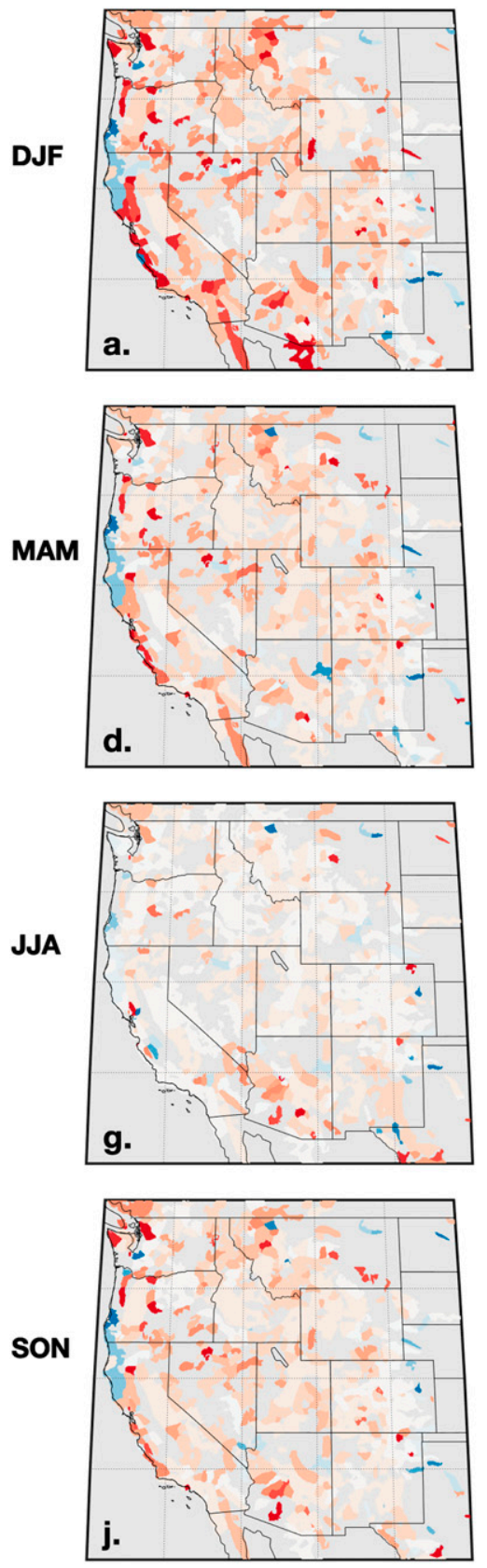

$125^{\circ} \mathrm{W} 120^{\circ} \mathrm{W} 115^{\circ} \mathrm{W} 110^{\circ} \mathrm{W} 105^{\circ} \mathrm{W} 100^{\circ} \mathrm{W}$

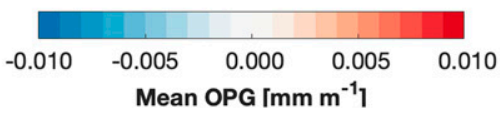

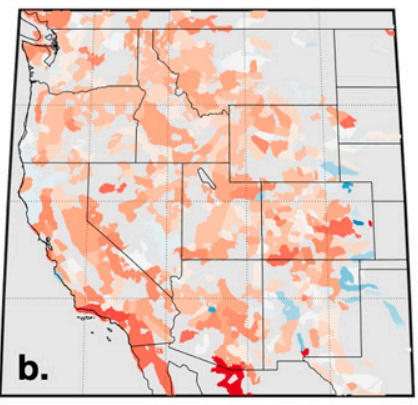
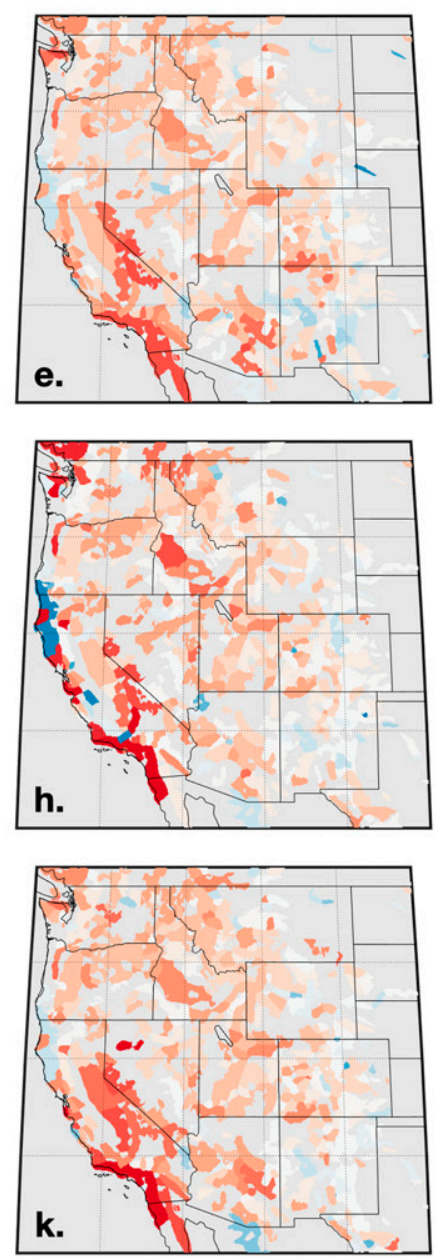

$125^{\circ} \mathrm{W} 120^{\circ} \mathrm{W} 115^{\circ} \mathrm{W} 110^{\circ} \mathrm{W} 105^{\circ} \mathrm{W} 100^{\circ} \mathrm{W}$

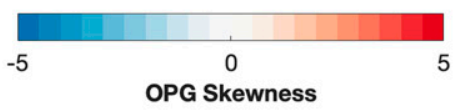

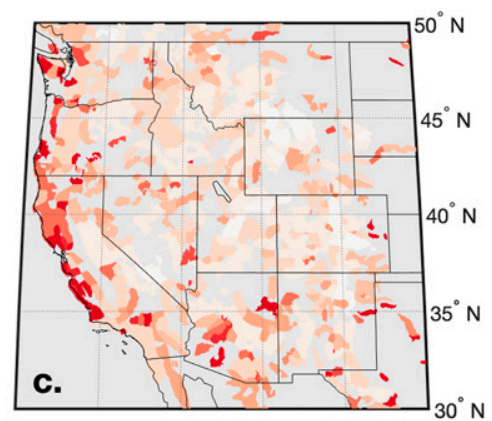
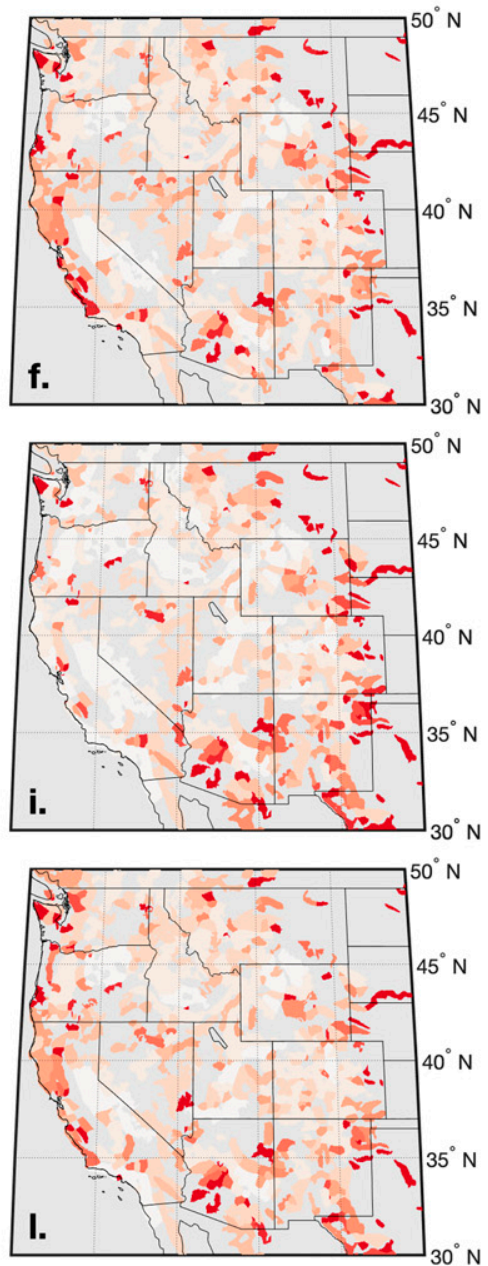

$125^{\circ} \mathrm{W} 120^{\circ} \mathrm{W} 115^{\circ} \mathrm{W} 110^{\circ} \mathrm{W} 105^{\circ} \mathrm{W} 100^{\circ} \mathrm{W}$

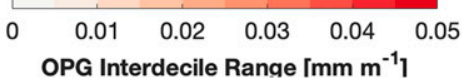

FIG. 5. (left) Mean of daily OPG values, (center) skewness of daily OPG, and (right) interdecile range (from the 10th to 90 th percentile) of daily OPG by meteorological season [(a)-(c) December-February (winter); (d)-(f) March-May (spring); (g)-(i) June-August (summer); (j)-(l) September-November (autumn)] and topographic facet.

with sufficient data. Seasonal maps of central tendency and distribution of OPG are shown by mean OPG, skewness, and interdecile range (IDR; 10th-90th percentile).
Spatially, OPG magnitudes are largest in coastal locations during the winter season (Fig. 5a), and most locations have positive OPG and positively skewed distributions, meaning precipitation commonly increases with 

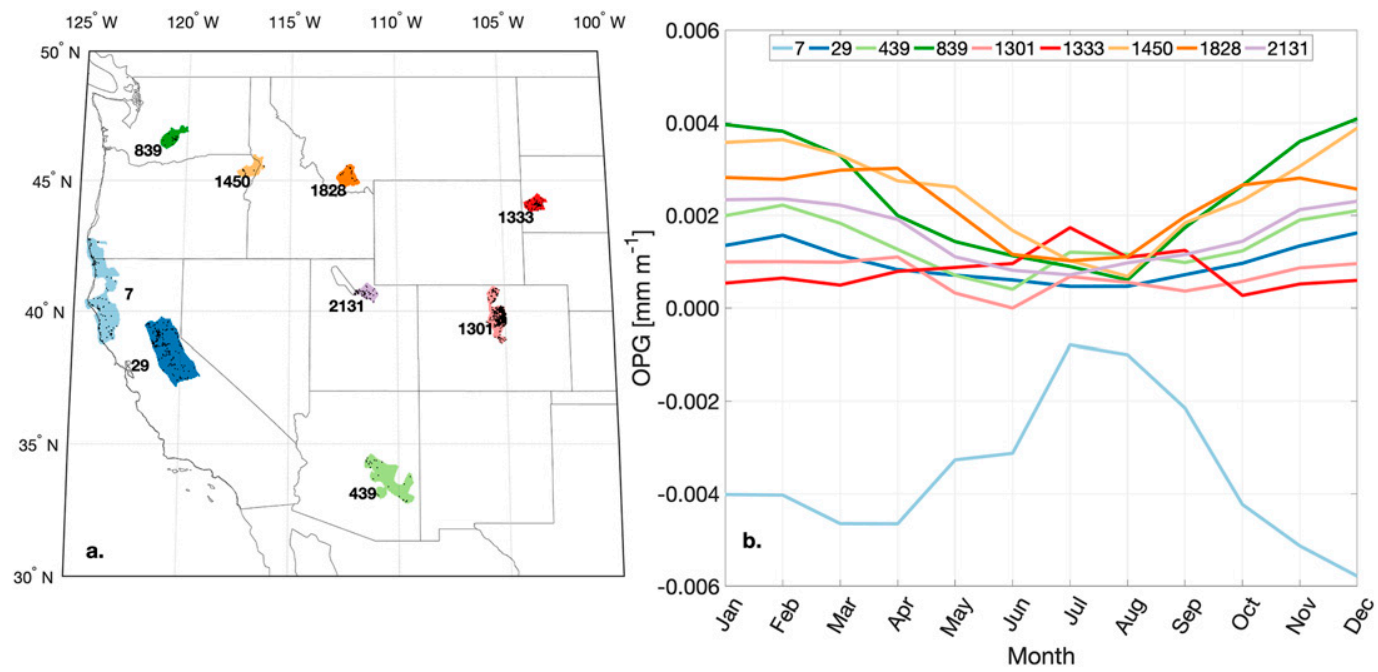

FIG. 6. (a) Several facets in the western United States (labeled by facet number) and associated precipitation observing station locations on each (black dots), and (b) annual cycle of OPG based on monthly means of the daily values of the OPG dataset for these facets (color coded).

elevation in the majority of the western United States (Fig. 5b). Positive skew indicates that there are more daily OPG with positive or large values than OPG with small or negative values. The IDR shows the variability of OPG within a season, and higher variability is also more common along the Pacific coast than in the interior western United States during the winter season (Fig. 5c). A small number of facets along the Pacific coast have negative mean OPG, and these facets also tend to have distributions minimally skewed or slightly negatively skewed.

Each of these quantities follows a seasonal cycle. Mean OPG tends to have its largest magnitude during the winter season and its smallest magnitude during the summer season, with intermediate values during the transition seasons of spring and autumn (left column of Fig. 5). The difference in magnitudes between coastal and interior OPG is much more apparent in the winter season than in the summer season, when OPG tends to be small and more uniform across the western United States. The annual cycle on monthly time scales for a subset of facets in various regions of the western United States is shown in Fig. 6, and further illustrates the cycle of OPG throughout the year for several facets, including one of the few facets with negative mean OPG for all seasons/months in northwestern coastal California (labeled as facet number seven). Characteristics such as orientation, elevation, mean winter-season precipitation, and numerical values of mean winter-season OPG and IDR for the facets exhibited in Fig. 6 are given in Table 2.

The seasonal cycle of skew is shown in the center column of Fig. 5. Facets with positive OPG tend to have positive skew; conversely, those with negative OPG tend to have negative skew. In the winter season, the largest values of skew are in the southern tier of the western United States including regions of southern Colorado, Arizona, and California. OPG skewness during transition seasons has maximum values in the southwest United States that are stronger than in the winter season but weaker than in the summer season, and smaller magnitude skewness values near the eastern portion of the domain. Skewness in the summer season is amplified along the Pacific coast more than other seasons. Histograms for winter-season OPG for several facets in the western United States are shown in Fig. 7, and highlight the tendency for positively skewed distributions of daily OPG values. However, even facets with positive mean OPG and positive winter-season skew do experience occasional negative daily values of OPG (although the likelihood of this is lower). Similarly, negative mean OPG and negatively skewed facets also experience some daily values with positive OPG.

The seasonal cycle of OPG IDR (right column of Fig. 5) showing the variability of OPG on individual facets is similar to that of mean OPG with the largest values in winter near the Pacific coast, decreasing to a minimum in the summer season. The transition seasons, and especially the summer season, show large IDR values in the eastern portion of the domain, which coincides with the change from complex and mountainous topography to the flatter Great Plains region of the central United States. The central and south-central portions of the domain have weak 
TABLE 2. For facets shown in Fig. 6, facet terrain orientation direction, elevation range and mean elevation of facet from DEM, mean winter-season (DJF) OPG values, interdecile range values, estimate of mean winter-season precipitation amount, and region.

\begin{tabular}{rcrccccl}
\hline \hline Facet No. & Orientation & $\begin{array}{c}\text { Elev } \\
\text { range }(\mathrm{m})\end{array}$ & $\begin{array}{c}\text { Mean } \\
\text { elev }(\mathrm{m})\end{array}$ & $\begin{array}{c}\text { Mean DJF OPG } \\
\left(\mathrm{mm} \mathrm{m}^{-1}\right) \times 10^{3}\end{array}$ & $\begin{array}{c}\text { DJF IDR } \\
\left(\mathrm{mm} \mathrm{m}^{-1}\right) \times 10^{3}\end{array}$ & $\begin{array}{c}\text { Mean DJF } \\
\text { precipitation }(\mathrm{mm})\end{array}$ & \multicolumn{1}{c}{ Region } \\
\hline 7 & WSW & $2-2160$ & 696 & -4.54 & 30.65 & 797 & Northern California coast \\
29 & WSW & $24-3721$ & 1159 & 1.58 & 7.68 & 585 & Sierra Nevada \\
439 & SSW & $609-3114$ & 1530 & 2.15 & 7.52 & 192 & Arizona \\
839 & ESE & $183-1878$ & 875 & 3.94 & 10.45 & 214 & Eastern Cascades \\
1301 & ENE & $1500-3996$ & 2586 & 0.96 & 2.76 & 81 & Colorado Front Range \\
1333 & ENE & $816-2133$ & 1341 & 0.61 & 4.01 & 34 & Black Hills \\
1450 & NNE & $339-2744$ & 1403 & 3.69 & 11.81 & 280 & Northwestern Idaho \\
1828 & NNW & $1394-2906$ & 2026 & 2.75 & 6.73 & 59 & Western Montana Rockies \\
2131 & WNW & $1272-3353$ & 2250 & 2.37 & 7.30 & 217 & Wasatch Mountains \\
\hline
\end{tabular}

annual cycles, where there are more similar IDR values for all seasons.

\section{c. Interannual $O P G$ variability}

Figure 8 shows the behavior of nine facets (identical to those in Table 2 and Fig. 6) from year to year using median winter OPG, inner quartile range (25th-75th percentile) of winter OPG, and IDR (10th-90th percentile) of winter-season OPG based on the 39-yr record of daily
OPG. OPGs of large magnitude and large variability in OPG are exhibited for facets near the Pacific Ocean, whereas inland facets tend to show OPGs of smaller magnitude and smaller interannual variability, much like the seasonal maps in Fig. 5.

\section{d. Base precipitation and dry layers}

Daily OPG regression calculations provide information about precipitation distribution on a facet including
7

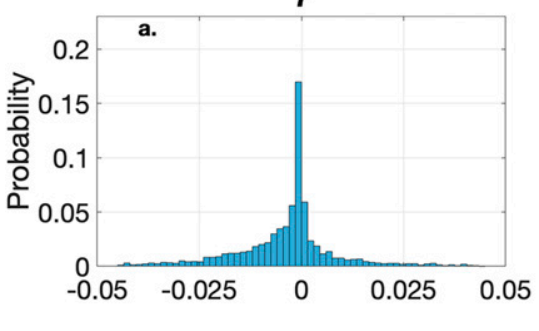

839

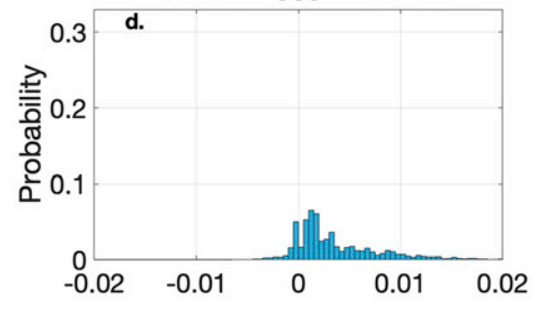

1450

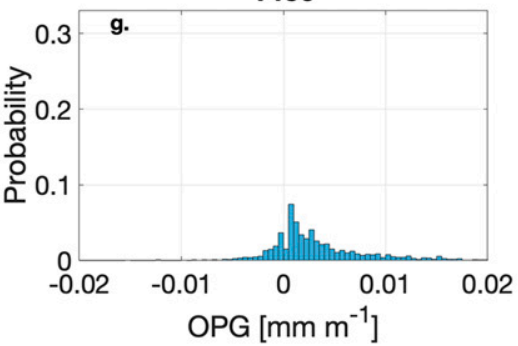

29

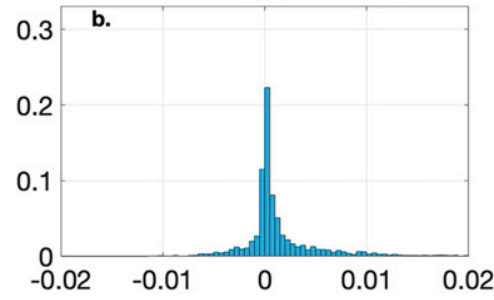

1301

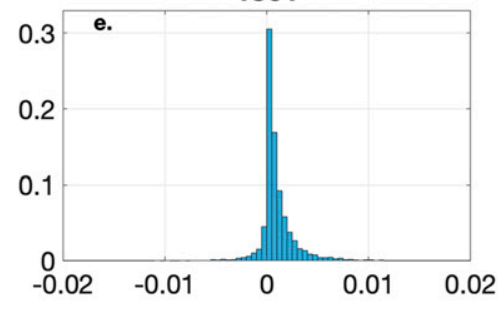

1828

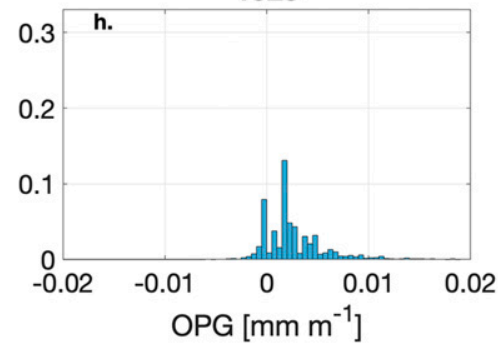

439

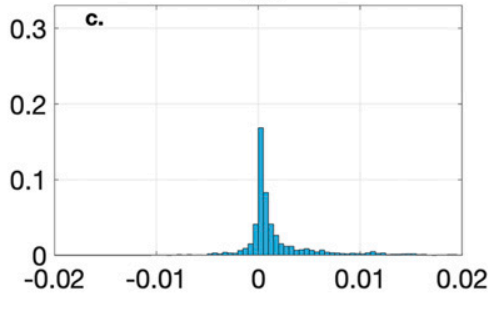

1333

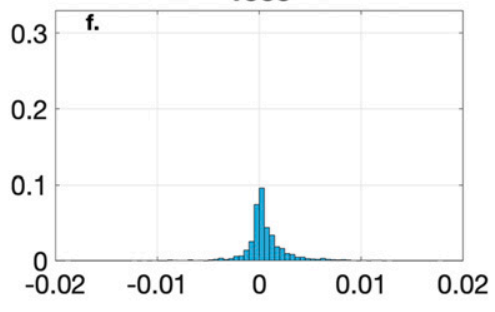

2131

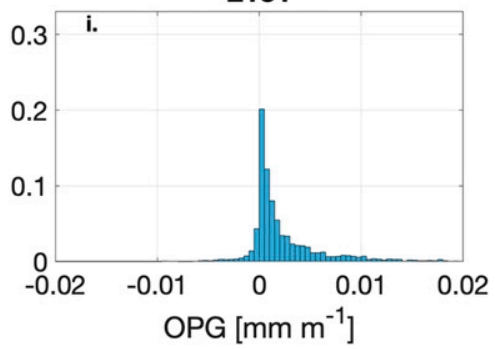

FIG. 7. Probability histograms of winter-season (DJF) OPG based on daily regression OPG values for the facets shown in Fig. 6, labeled by facet number. Note the different axis limits for (a). 

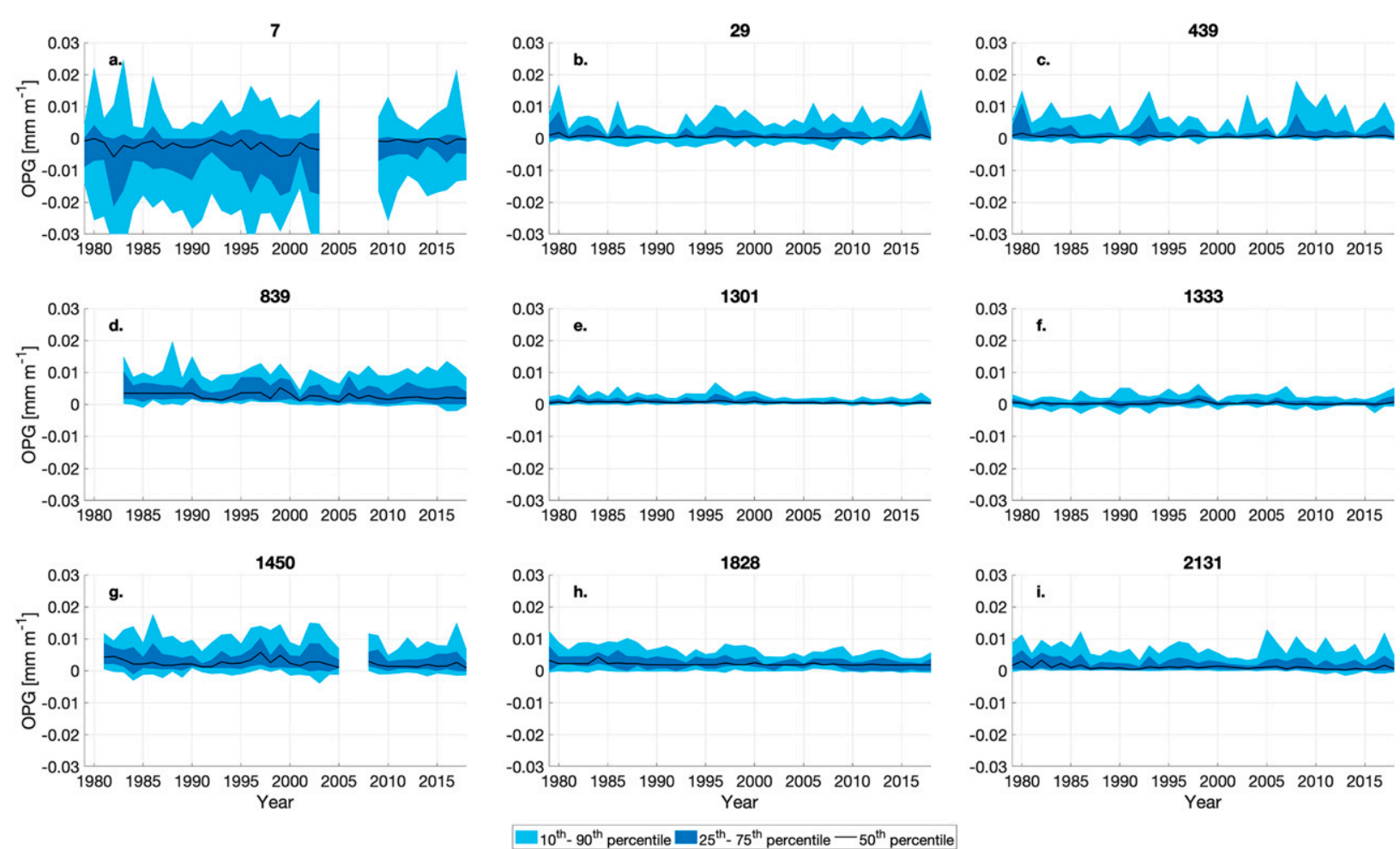

FIG. 8. Winter-season (DJF) OPG percentiles based on daily OPG values for the facets shown in Fig. 6.

the amount of base precipitation $P_{0}$ as well as dry layers at the lowest or highest elevations in the facet. Mean winter-season base precipitation amounts at the lowest elevation in each facet are shown in Fig. 9a, calculated from daily OPG regressions and Eq. (4). Values are large for coastal locations/facets, and are smaller for interior locations in the western United States.

Smaller base precipitation amounts tend to coincide with deeper lower-level dry layers in the lowest elevations on the facet. This is due to daily facet values of $P_{0}$ being assigned a value of zero for days with precipitation starting above facet base elevation. Mean winter-season lower dry-layer depth $\delta z_{\ell}$ by facet is shown in Fig. $9 \mathrm{~b}$. Low-level dry layers are likely dependent on the typical moisture profile and lifting condensation level on facets. The interior western United States often experiences lower dry layers during the winter season, while coastal locations with moister low-level conditions tend to have small to negligible dry-layer depths since precipitation amounts are often large at the facet base.

Recall that upper-level dry layers can arise when the OPG is negative, based on Eq. (5). Mean upper-level dry-layer depth $\delta z_{u}$ by facet for winter-season precipitation days is shown in Fig. 9c. The spatial pattern of
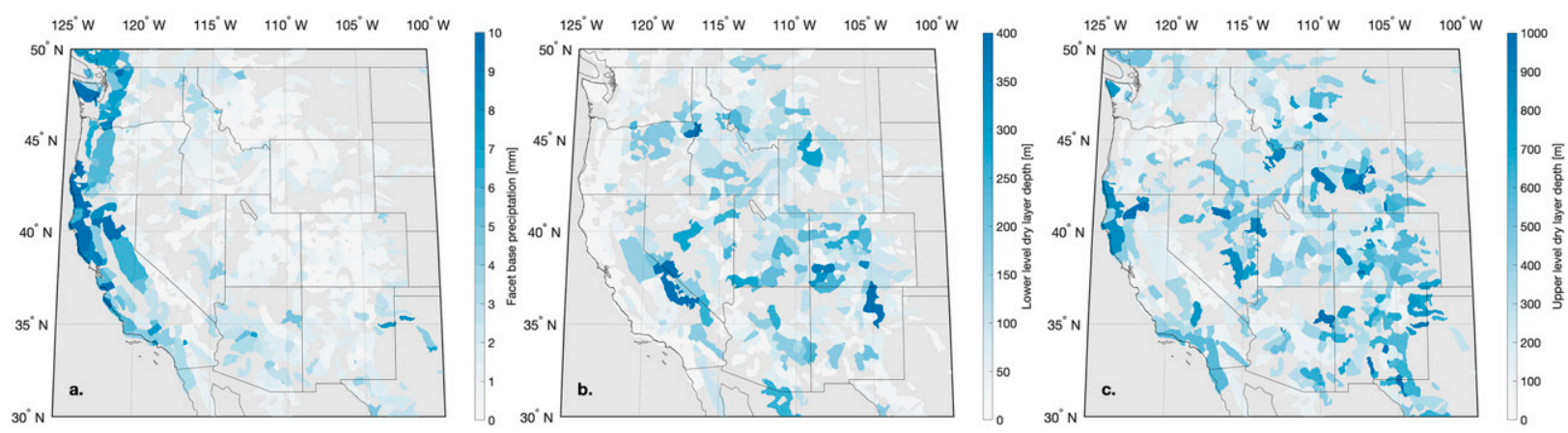

FIG. 9. (a) Mean daily base precipitation amount $P_{0}(\mathrm{~mm})$ at the facet base calculated from winter-season regression values, (b) mean depth of the lower dry layer $\delta z_{\ell}$ for winter-season days, and (c) mean depth of upper-level dry layer $\delta z_{u}$ for winter-season days. 

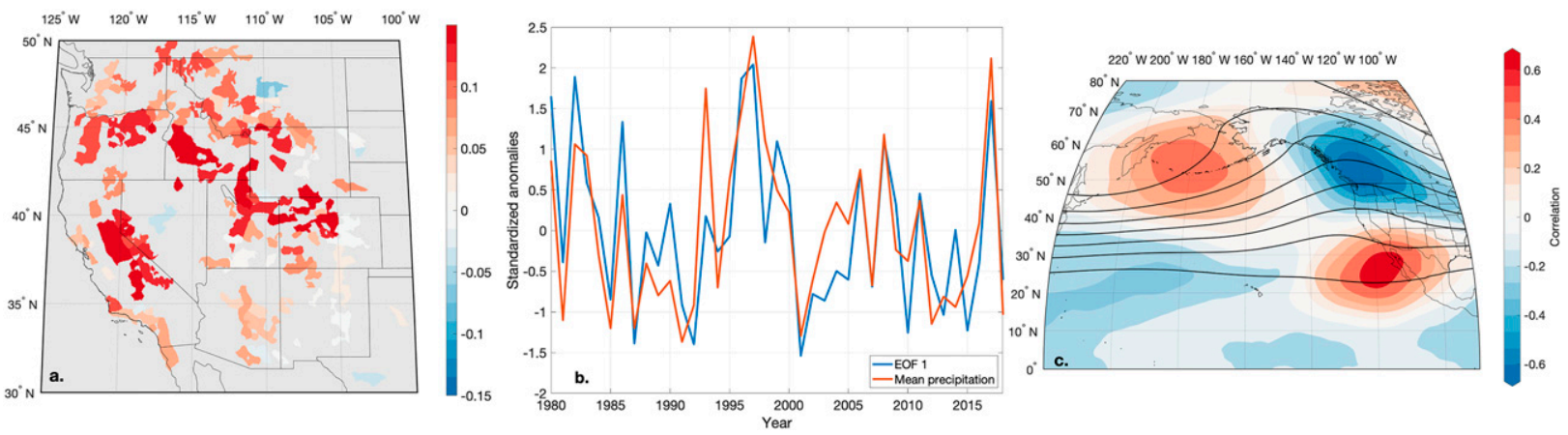

FIG. 10. (a) Coefficient values for the 120 facets in the EOF analysis for the first principal component (PC1), (b) time series of standardized anomalies of PC1 and the mean precipitation amount for the facets in the analysis for each winter season, and (c) correlations between PC1 and winter-season mean 500-hPa geopotential height for the 39-yr period (shading) and average winter-season 500-hPa geopotential height conditions for the $39-\mathrm{yr}$ period (contours every $100 \mathrm{~m}$ ).

upper-level dry layers is less differentiated between coastal and interior regions than lower-level dry layers. However, since the majority of facets in the western United States have positive OPG for winter-season days, and since the upper-level dry layer can only exist for days with negative OPG, the occurrence of upperlevel dry layers is less common than lower-level dry layers in general based on the regression method.

\section{e. EOF analysis}

\section{1) FirST PRINCIPAL COMPONENT}

The first principal component of OPG (PC1) explains $21 \%$ of the variance in winter mean OPG. The first panel of Fig. 10 shows the loading pattern of the first principal component. In this mode, generally all facets analyzed in our analysis are given positive coefficients, meaning the driver in this pattern affects most of the western United States in a similar way. PC1 is highly positively correlated with mean precipitation for the
120 -facet subset over the winter season $(r=0.79)$ as shown in Fig. 10b. So, for years with high precipitation over the western United States, facet OPG tends to be of large magnitude as well.

The associated correlation map between PC1 and each grid point of 500-hPa geopotential height is shown in Fig. 10c, along with mean winter-season 500-hPa geopotential height contours for the $39-y r$ record. This correlation pattern shows the locations important to explaining the first mode of western United States OPG variability. To explore this pattern in more detail, the 500-hPa geopotential height pattern favoring conditions of high OPG and high precipitation for the western United States (large values of PC1) is shown as anomalies from the mean conditions in Fig. 11a for winters with $\mathrm{PC} 1$ in the upper quartile. A decrease in intensity of ridging over the Pacific Northwest, a decreased height field in the midlatitude central Pacific, a decrease in amplitude/intensity of the Aleutian low, and a slight westward shift in ridging southwest of
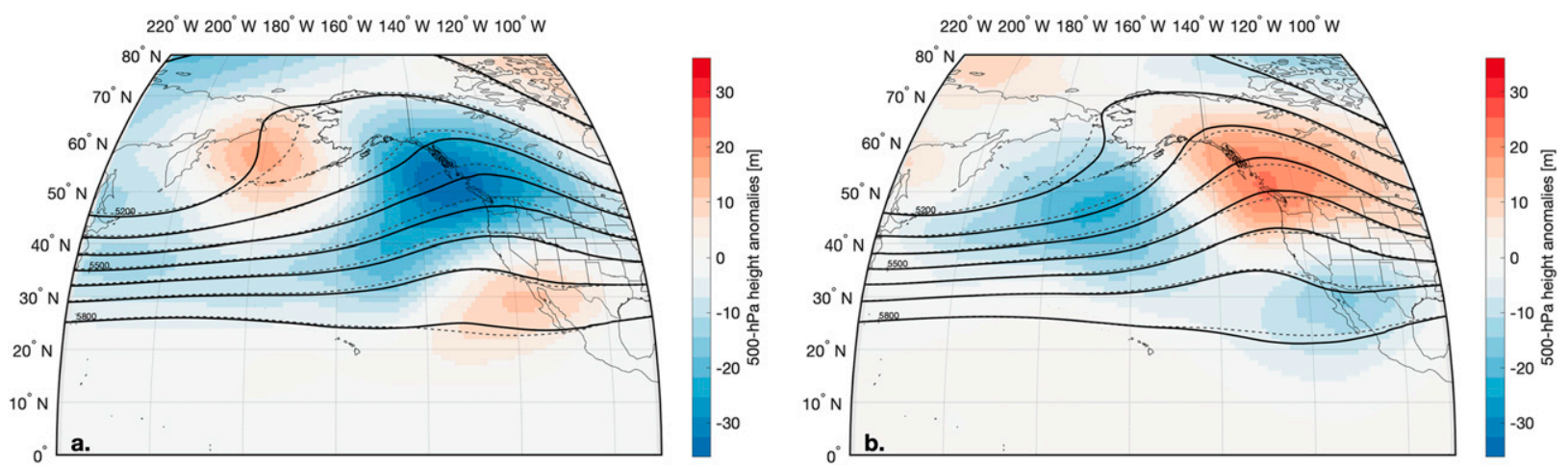

FIG. 11. (a) Mean DJF 500-hPa geopotential height anomalies for winters in the (a) upper and (b) lower quartiles of the first principal component (shading), and mean DJF 500-hPa geopotential height for these subsets (black contours; m). In (a) and (b), mean DJF 500-hPa geopotential height for all years is indicated by gray dashed contours. 

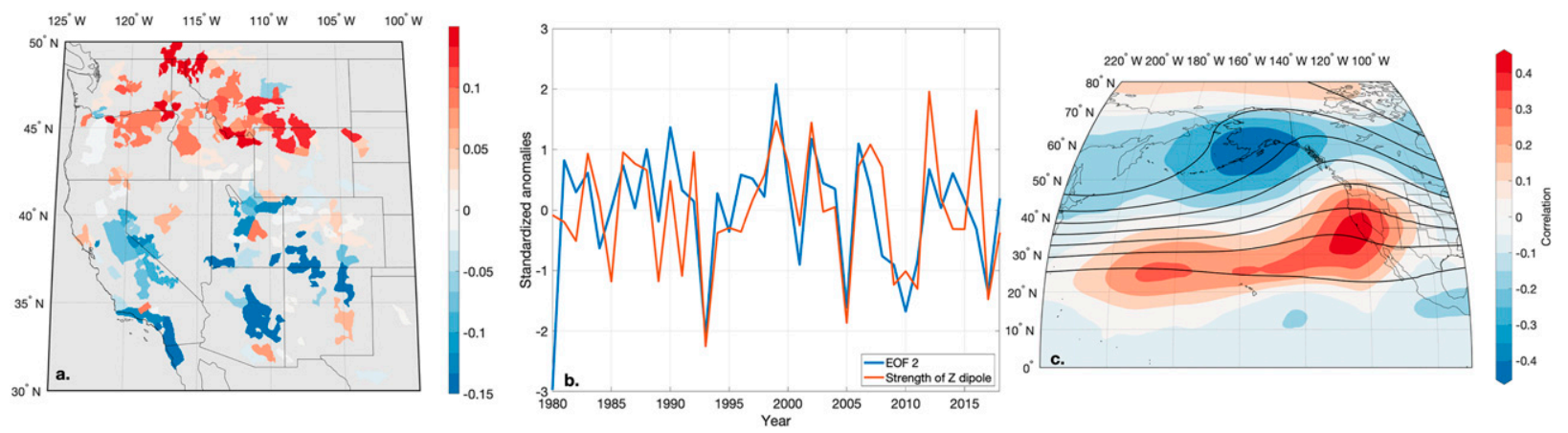

FIG. 12. Similar to Fig. 10, but showing (a) coefficient values for the 120 facets in EOF analysis for the second principal component (PC2), (b) time series of standardized anomalies of PC2 and the 500-hPa geopotential height dipole index between coastal central California and the Gulf of Alaska, and (c) correlations between PC2 and winter-season mean 500-hPa geopotential height for the 39-yr period (shading) and average winter-season 500-hPa geopotential height conditions for the 39-yr period (contours every $100 \mathrm{~m}$ ).

Southern California leads to above-average precipitation amounts and above-normal OPG magnitude throughout the western United States.

In contrast, a 500-hPa geopotential height pattern that would favor the opposite conditions (low OPG and low mean precipitation across the western United States) is shown as height anomalies from the mean conditions in Fig. 11b for winters with the first principal component in the lower quartile. In general, these characteristics are increased Aleutian low intensity, increased ridging over the Pacific Northwest and Gulf of Alaska, a region of increased geopotential heights in the midlatitude central Pacific, and slightly increased strength of the weak mean trough near Baja California, resulting in a more amplified pattern over the eastern Pacific Ocean with stronger split-flow conditions into the western United States.

\section{2) SECOND PRINCIPAL COMPONENT}

The second principal component of OPG (PC2) explains $12 \%$ of the variance in winter mean OPG. In this mode, there is a north/south dipole in the loading pattern, meaning the northern and southern portions of the western continental United States tend to have oppositely signed OPG anomalies in this mode (Fig. 12a).

Winter seasons with amplified ridging off of the western coast of the United States in addition to a strengthened Aleutian low tend to produce a region of above-average OPG in the northern half of the western United States and a region of below-average OPG in the southern half of the western United States. A 500-hPa geopotential height dipole index between central coastal California and the Gulf of Alaska is moderately positively correlated with the time series for the second principal component $(r=0.60)$ and is shown in Fig. 12b. This dipole index is defined as the mean winter-season height differences between $4^{\circ}$ latitude by $4^{\circ}$ longitude areas centered at the maximum $\left(35^{\circ} \mathrm{N}, 125^{\circ} \mathrm{W}\right)$ and minimum $\left(58^{\circ} \mathrm{N}, 156^{\circ} \mathrm{W}\right)$ correlation locations shown in the correlation map between the second principal component and each grid point of 500-hPa geopotential height shown in Fig. 12c. An anomalously small value for the second principal component in the first year of record (winter season 1980) while the dipole index was near zero was due to a westward shifted and more north/south oriented dipole than the other years. The westward shift of the dipole coincided with highly above-average OPG in the southern tier of the western United States and substantially below-average OPG in the northern tier.

Figure 13 shows anomalies from the mean $500-\mathrm{hPa}$ geopotential height field as shading and contours for the 39-yr period for upper-quartile values (above-average OPG in the north, below-average OPG in the south) and lower-quartile values (below-average OPG in the north, above-average OPG in the south) for PC2. The former involves strong ridging along the Pacific coast of the United States in combination with a strong trough in the Gulf of Alaska, while the latter involves a weaker dipole or overall switch in dipole magnitudes.

\section{Discussion and conclusions}

OPG seasonal patterns are likely due to the nature of precipitation systems in different times of year for the western United States. Cool-season systems are often synoptic in scale, with significant moisture transport and dynamics. These well-organized, large-scale systems produce much of the annual precipitation for much of the western United States. In contrast, localized convection tends to dominate during the warmer seasons with lower overall precipitation amounts.

OPG spatial patterns are likely also related to the nature of precipitation systems. Landfalling midlatitude 

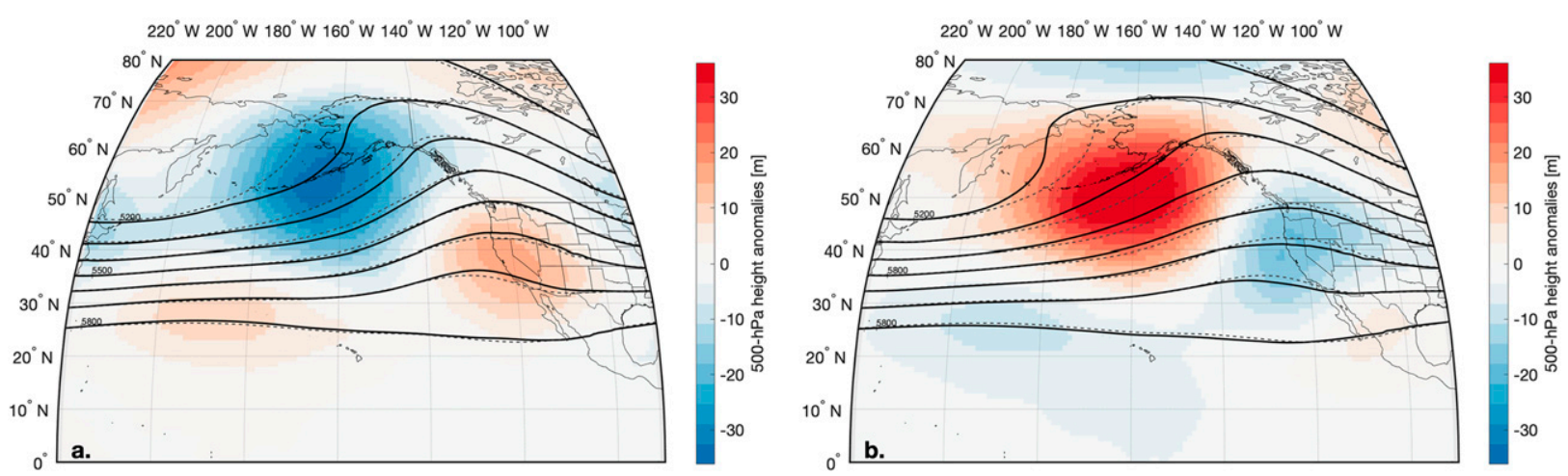

FIG. 13. As in Fig. 11, but for the second principal component.

cyclones in the cool season are known to bring heavy precipitation to coastal lowlands and topographic barriers near coasts, then become less moist moving inland. Spatial and seasonal patterns imply a relationship between OPG magnitude, precipitation amount, and OPG variability, where locations with high precipitation tend to have high-magnitude OPG but also larger variability in OPG. Since low precipitation days are much more common than high-precipitation days, we would expect a large probability of small OPG days to show up in binned distributions of OPG daily values. The relationship between precipitation amount and OPG magnitude can be visualized by the histograms in Fig. 7, where the distribution or probability of winter-season daily OPG essentially reflects the distribution of precipitation event size. In regions where a significant amount of seasonal snow accumulation is driven by extreme events [such as the Sierra Nevada, as highlighted by Huning and Margulis (2017)], the relationship between OPG and precipitation amount may be critical in a water resources perspective.

Some facets on the eastern edge of the domain (on the western edges of the Great Plains) exhibit high variability, especially during the summer seasons. We expect that this is due to convective storms over these facets combined with facets having relatively small elevation gradients, so that the regression OPG is highly variable from localized precipitation during convective storms on facets. This may also be the case in the southwestern United States in late summer when impacts from the North American monsoon produce convective storms.

Spatial patterns of base precipitation and lower-level dry layers show the prominence of rain shadowing from subsidence, especially in the lee of the Cascade Mountains and the Sierra Nevada. Another reason for the prominence of lower-level dry layers in the interior western United States may be the presence of drier air masses ahead of the cool-season midlatitude cyclones, which could be responsible for higher cloud bases and increased subcloud evaporation, therefore limiting low-elevation precipitation. While upper-level and lower-level dry layers could physically exist simultaneously on any specific day, the linear regression approach used in this analysis would not be able to capture that specific type of daily precipitation distribution.

EOF analysis suggests that interannual variability in OPG is related to precipitation amount, which is influenced by large-scale patterns over the Pacific Ocean. A more zonally oriented flow into the western United States seems to be responsible for creating high precipitation and high-magnitude OPG. In contrast, height patterns that create a split flow into the northern and southern tiers of the western United States are related to the opposite conditions. The zonally oriented flow would direct storm systems into the central portions of the western United States, and a split flow pattern would deflect systems to the north or south. While the second principal component has a clear north/south pattern, this mode is not significantly correlated with ENSO indices, such as the multivariate ENSO index (Wolter and Timlin 1993, 1998).

While correlation patterns between principal components from EOF analysis and sea surface temperature (SST) did not clearly resemble traditional ENSO patterns, SST composite anomalies for upper/lower-quartile winter years (analogous to those in Figs. 11 and 13) do have characteristics of the traditional patterns. The upper-quartile EOF 1 SST composite has similarities to traditional La Niña SST patterns with anomalously cold regions in the equatorial Pacific extending northward toward Baja California, as well as in the southern Gulf of Alaska. The lower-quartile EOF 1 SST composite resembles the El Niño phase with anomalously warm SST in the central equatorial Pacific and along the western coast of North America and anomalously cool SST from the western equatorial Pacific extending to north of the Hawaiian islands. The upper-quartile EOF 2 SST composite did not feature a warm or cool region in the 
equatorial Pacific, but the lower-quartile EOF 2 composite showed greater resemblance to traditional $\mathrm{La}$ Niña SST patterns.

Our quality controlled OPG time series calculated from regressions of stations precipitation and elevation have similar magnitudes and spatial patterns of OPG as those calculated by Praskievicz and Bartlein (2014) using long-term PRISM gridded precipitation maps. While our results are more delineated due to facet boundaries than those calculated from PRISM maps, similar patterns are visible between the two methods. Both analyses pick up on differences between summer and winter OPG magnitudes and identify similar spatial patterns of OPG magnitude, especially for mountainous areas in the Cascade Range of Washington and Oregon, the Rocky Mountains in northern Montana, and the Park Range and Medicine Bow Range in northern Colorado and southern Wyoming [compare our winter-season mean OPG in Fig. 5a with Fig. 3e in Praskievicz and Bartlein (2014)].

Additional quality control procedures to the OPG dataset were explored but not implemented because of the cdf span quality control producing consistent and plausible time series. A station density (number of stations per kilometer squared) threshold was explored and we found that the cdf span threshold of $40 \%$ generally corresponded to a station density of approximately 1 station per $2000 \mathrm{~km}^{2}$.

Local effects to orographic enhancement have not been extensively studied, but results from a low-level blocking event in the northern California coastal mountains by Neiman et al. (2002) suggest that negative OPG could arise from certain blocked cases. The region of study where low-level blocking occurred coincides with our coastal northern California facet, which is one of the few facets in our analysis with negative mean OPG and negative skew of daily OPG. Recurrent negative OPG values on some coastal facets may have more to do with facet shape/size and station placement on the facet. Landfalling systems upon the coast may have unique precipitation distributions where areas just inland of the coast have higher precipitation amounts than similar elevations slightly more inland. Combined with the lack of precipitation observing stations in some of the higher terrain, strong negative OPG (and resulting upper-level day layers) may be an artifact based on the data and methods used.

Splitting up terrain via the facet algorithm is one of the limitations of this study. While the facet shapes and sizes seem reasonable, the exact optimization of facet sizing to produce what physically occurs on topography is unknown. Nevertheless, it generally follows the methods used by Gibson et al. (1997) and Daly et al. (1994, 2008), which have been heavily peer reviewed. We also assume that the regression OPG is representative of the area of the entire facet, which may be another limitation as smaller-scale variations of precipitation in complex terrain may be at play. Geographic and seasonal differences in precipitation system coherency across the western United States as studied by Parker and Abatzoglou (2015) and the interaction with topography could also impact the daily values of OPG. The importance of observations in the western United States is highlighted and many areas across the complex terrain of the western United States could benefit from a more dense array of observations of precipitation. Many of our facets were unable to be analyzed due to insufficient precipitation stations to calculate a reliable OPG, mainly in more remote areas of the western United States such as the Great Basin. Also, our experimentation with using only certain networks or a longer accumulation period to calculate daily OPG shows the sensitivity of our results to stations used.

Our facet boundaries and assigning stations to facets produces some uncertainty in regression values, especially when only two stations are used to calculate the daily OPG. However, less than $9 \%$ of the total daily OPG values are based on the regression of exactly two station elevations and precipitation amounts, and these regression values generally have only been used in the quality controlled time series when they match the magnitude and variability of OPG from later in the record when more stations are used in the regression. For daily regressions on facets with sufficient stations to analyze the residuals and asses the goodness of linear fit (mainly larger facets), we do not find any apparent structure in the residual values or dependency of the residuals on latitude or longitude. In addition, a broad range of station sample sizes has been used to compare and understand high-elevation and low-elevation precipitation, such as Steenburgh (2003) (2 stations), Kunz and Kottmeier (2006) (2 stations), Neiman et al. (2002) (2 stations), Dettinger et al. (2004) (3 low-elevation and 3 high-elevation stations), and Lundquist et al. (2010) (124 stations across varying elevations).

This paper presents the spatial and temporal patterns of OPG in the western United States based on a longterm record of daily precipitation amounts at observing stations and identifies some of the drivers of variability for OPG. The patterns that arise are complex and often heterogeneously delineated by facet boundaries, but appear plausible based on storm track characteristics, coastal proximity, and topographic barrier positions and orientations. In most western United States locations OPG tends to be positive with larger magnitude OPG and larger variability for locations with coastal proximity. 
Most distributions of daily OPG on a seasonal basis have positive skew. A few locations experience negative OPG on average, and these locations tend to have negatively skewed distributions of daily OPG. The highest magnitude of OPG tends to occur in the winter season, whereas the minimum magnitude of OPG occurs in the summer season. Although this study identified spatial and temporal patterns of OPG and some of the seasonal and interannual variability in OPG, future work in determining drivers of variability of OPG on shorter (daily) time scales is anticipated, with the goal of being able to identify and understand predictors of OPG to use for improving cool-season precipitation forecast accuracy in the western United States.

Acknowledgments. We thank the University of Utah Center for High Performance Computing (CHPC) for computational resources and computer-support services. We thank two anonymous reviewers for providing feedback to improve this paper. This article is based on research supported by the NOAA/National Weather Service CSTAR Program through Grant NA17NWS4680001. Any opinions, findings, and conclusions or recommendations expressed herein are those of the authors and do not necessarily reflect those of the NOAA/National Weather Service.

\section{REFERENCES}

Brunsdon, C., J. McClatchey, and D. Unwin, 2001: Spatial variations in the average rainfall-altitude relationship in Great Britain: An approach using geographically weighted regression. Int. J. Climatol., 21, 455-466, https://doi.org/10.1002/ joc.614.

Burt, T., and J. Holden, 2010: Changing temperature and rainfall gradients in the British Uplands. Climate Res., 45, 57-70, https://doi.org/10.3354/cr00910.

Chow, F. K., S. F. D. Wekker, and B. J. Snyder, Eds., 2013: Mountain Weather Research and Forecasting. Springer, 564 pp., https://doi.org/10.1007/978-94-007-4098-3.

Daly, C., R. P. Neilson, and D. L. Phillips, 1994: A statisticaltopographic model for mapping climatological precipitation over mountainous terrain. J. Appl. Meteor., 33, 140-158, https://doi.org/10.1175/1520-0450(1994)033<0140:ASTMFM> 2.0.CO;2.

—, M. Halbleib, J. I. Smith, W. P. Gibson, M. K. Doggett, G. H. Taylor, J. Curtis, and P. P. Pasteris, 2008: Physiographically sensitive mapping of climatological temperature and precipitation across the conterminous United States. Int. J. Climatol., 28, 2031-2064, https://doi.org/10.1002/joc.1688.

Dee, D. P., and Coauthors, 2011: The ERA-Interim reanalysis: Configuration and performance of the data assimilation system. Quart. J. Roy. Meteor. Soc., 137, 553-597, https://doi.org/ 10.1002/qj.828

Dettinger, M., K. Redmond, and D. Cayan, 2004: Winter orographic precipitation ratios in the Sierra Nevada-Large-scale atmospheric circulations and hydrologic consequences. J. Hydrometeor., $\mathbf{5}$, 1102-1116, https://doi.org/10.1175/JHM-390.1.
Durre, I., M. J. Menne, and R. S. Vose, 2008: Strategies for evaluating quality assurance procedures. J. Appl. Meteor. Climatol., 47, 1785-1791, https://doi.org/10.1175/2007JAMC1706.1.

,-- B. E. Gleason, T. G. Houston, and R. S. Vose, 2010: Comprehensive automated quality assurance of daily surface observations. J. Appl. Meteor. Climatol., 49, 1615-1633, https:// doi.org/10.1175/2010JAMC2375.1.

EROSC, 2017: Global 30 arc-second elevation (GTOPO30). U.S. Geological Survey, accessed 1 November 2018, https:// doi.org/10.5066/f7df6pqs.

Gibson, W., C. Daly, and G. Taylor, 1997: Derivation of facet grids for use with the PRISM model. 10th Conf. on Applied Climatology, Reno, NV, Amer. Meteor. Soc., 208-209.

Gonzalez, R. C., R. E. Woods, and S. L. Eddins, 2004: Digital Image Processing Using MATLAB. Pearson Education, $620 \mathrm{pp}$.

Gowan, T. M., W. J. Steenburgh, and C. S. Schwartz, 2018: Validation of mountain precipitation forecasts from the convection-permitting NCAR ensemble and operational forecast systems over the western United States. Wea. Forecasting, 33, 739-765, https://doi.org/10.1175/WAF-D-17-0144.1.

Hannachi, A., I. T. Jolliffe, and D. B. Stephenson, 2007: Empirical orthogonal functions and related techniques in atmospheric science: A review. Int. J. Climatol., 27, 1119-1152, https:// doi.org/10.1002/joc.1499.

Haralick, R. M., and L. G. Shapiro, 1992: Computer and Robot Vision. Vol. 1. Addison-Wesley Longman, $630 \mathrm{pp}$.

Henn, B., A. J. Newman, B. Livneh, C. Daly, and J. D. Lundquist, 2018: An assessment of differences in gridded precipitation datasets in complex terrain. J. Hydrol., 556, 1205-1219, https:// doi.org/10.1016/j.jhydrol.2017.03.008.

Huning, L. S., and S. A. Margulis, 2017: Climatology of seasonal snowfall accumulation across the Sierra Nevada (USA): Accumulation rates, distributions, and variability. Water Resour. Res., 53, 6033-6049, https://doi.org/10.1002/2017WR020915. , and - 2018: Investigating the variability of high-elevation seasonal orographic snowfall enhancement and its drivers across Sierra Nevada, California. J. Hydrometeor., 19, 47-67, https://doi.org/10.1175/JHM-D-16-0254.1.

Kunz, M., and C. Kottmeier, 2006: Orographic enhancement of precipitation over low mountain ranges. Part I: Model formulation and idealized simulations. J. Appl. Meteor. Climatol., 45, 1025-1040, https://doi.org/10.1175/JAM2389.1.

Lewis, W. R., W. J. Steenburgh, T. I. Alcott, and J. J. Rutz, 2017: GEFS precipitation forecasts and the implications of statistical downscaling over the western United States. Wea. Forecasting, 32, 1007-1028, https://doi.org/10.1175/WAF-D-16-0179.1.

Li, D., M. L. Wrzesien, M. Durand, J. Adam, and D. P. Lettenmaier, 2017: How much runoff originates as snow in the western United States, and how will that change in the future? Geophys. Res. Lett., 44, 6163-6172, https://doi.org/10.1002/2017GL073551.

Luce, C. H., J. T. Abatzoglou, and Z. A. Holden, 2013: The missing mountain water: Slower westerlies decrease orographic enhancement in the Pacific Northwest USA. Science, 342, 13601364, https://doi.org/10.1126/science.1242335.

Lull, H. W., and L. Ellison, 1950: Precipitation in relation to altitude in central Utah. Ecology, 31, 479-484, https://doi.org/10.2307/1931507.

Lundquist, J. D., J. R. Minder, P. J. Neiman, and E. Sukovich, 2010: Relationships between barrier jet heights, orographic precipitation gradients, and streamflow in the northern Sierra Nevada. J. Hydrometeor., 11, 1141-1156, https://doi.org/10.1175/ 2010JHM1264.1.

Menne, M. J., and Coauthors, 2012a: Global Historical Climatology Network - Daily (GHCN-Daily), version 3.22. NOAA National 
Centers for Environmental Information, accessed 20 March 2018, https://doi.org/10.7289/v5d21vhz.

, I. Durre, R. S. Vose, B. E. Gleason, and T. G. Houston, 2012b: An overview of the Global Historical Climatology NetworkDaily database. J. Atmos. Oceanic Technol., 29, 897-910, https:// doi.org/10.1175/JTECH-D-11-00103.1.

Neiman, P. J., F. M. Ralph, A. B. White, D. E. Kingsmill, and P. O. G. Persson, 2002: The statistical relationship between upslope flow and rainfall in California's coastal mountains: Observations during CALJET. Mon. Wea. Rev., 130, 1468-1492, https://doi.org/10.1175/1520-0493(2002)130<1468:TSRBUF> 2.0.CO;2.

Parker, L. E., and J. T. Abatzoglou, 2015: Spatial coherence of extreme precipitation events in the northwestern United States. Int. J. Climatol., 36, 2451-2460, https://doi.org/10.1002/joc.4504.

Praskievicz, S., 2017: Downscaling climate-model output in mountainous terrain using local topographic lapse rates for hydrologic modeling of climate-change impacts. Phys. Geogr., 39, 99-117, https://doi.org/10.1080/02723646.2017.1378555.

_- and P. Bartlein, 2014: Hydrologic modeling using elevationally adjusted NARR and NARCCAP regional climate-model simulations: Tucannon River, Washington. J. Hydrol., 517, 803-814, https://doi.org/10.1016/j.jhydrol.2014.06.017.

Serreze, M. C., M. P. Clark, R. L. Armstrong, D. A. McGinnis, and R. S. Pulwarty, 1999: Characteristics of the western United States snowpack from snowpack telemetry (SNOTEL) data. Water Resour. Res., 35, 2145-2160, https://doi.org/10.1029/ 1999WR900090.

Sevruk, B., 1997: Regional dependency of precipitation-altitude relationship in the Swiss Alps. Climatic Change, 36, 355-369, https://doi.org/10.1023/A:1005302626066.
Singh, V., and M. K. Goyal, 2016: Analysis and trends of precipitation lapse rate and extreme indices over north Sikkim eastern Himalayas under CMIP5ESM-2M RCPs experiments. Atmos. Res., 167, 34-60, https://doi.org/10.1016/ j.atmosres.2015.07.005.

Smith, R. B., and I. Barstad, 2004: A linear theory of orographic precipitation. J. Atmos. Sci., 61, 1377-1391, https://doi.org/ 10.1175/1520-0469(2004)061<1377:ALTOOP>2.0.CO;2.

Steenburgh, W. J., 2003: One hundred inches in one hundred hours: Evolution of a Wasatch Mountain winter storm cycle. Wea. Forecasting, 18, 1018-1036, https://doi.org/10.1175/1520-0434(2003) 018<1018:OHIIOH $>2.0 . \mathrm{CO} ; 2$.

Wang, L., R. Chen, Y. Song, Y. Yang, J. Liu, C. Han, and Z. Liu, 2017: Precipitation-altitude relationships on different timescales and at different precipitation magnitudes in the Qilian Mountains. Theor. Appl. Climatol., 134, 875-884, https:// doi.org/10.1007/s00704-017-2316-1.

Wolter, K., and M. S. Timlin, 1993: Monitoring ENSO in COADS with a seasonally adjusted principal component index. Proc. 17th Climate Diagnostics Workshop, Norman, OK, NOAA/NMC/CAC, NSSL, Oklahoma Climate Survey, CIMMS, and the School of Meteorology, University of Oklahoma, 52-57 pp.

— How does 1997/98 rank? Weather, 53, 315-324, https://doi.org/ 10.1002/j.1477-8696.1998.tb06408.x.

Zhu, X., X. Qiu, Y. Zeng, W. Ren, B. Tao, H. Pan, T. Gao, and J. Gao, 2017: High-resolution precipitation downscaling in mountainous areas over China: Development and application of a statistical mapping approach. Int. J. Climatol., 38, 77-93, https://doi.org/10.1002/joc.5162. 